\section{PARTIAL AND COMPLETE DISLOCATION OF THE SEMILUNAR CARTILAGE OF THE KNEE; OPERATION ON SIX CASES.}

By ARTHUR E. BARKER, F.R.C.S. ENG. AND IREL., PROFESSOR OF THE PRINCIPLES AND PRACTICE OF SURGERY, AND
PROFESSOR OF CLINICAL SURGERY AT UNIVERSITY COLLEGE, AND SURGEON TO UNIVERSITY COLLEGE HOSPITAL.

THE mechanism of the knee-joint has always appeared to me to be one of the most interesting problems in anatomy, but one at the same time far from being satisfactorily explained. To call the knee simply a hinge-joint is quite an inadequate description, though true up to a certain point. It is a hinge undoubtedly, but a hinge with far more complex movements and limitations of movement than are suggested in the name. The difficulties in explaining the details of movement in the joint will probably never be entirely cleared up by anatomical studies on the dead body. So many changes take place after death in the tone of the muscles and in the tension of the ligaments when the capsule has been more or less completely removed that the normal movements within the joint are probably rarely or ever seen post mortem. But in the living subject the case is otherwise, and it is possible to examine many points which after death would probably be considerably altered.

Having operated on the knee-joint very fully in a great number of cases its internal anatomy in vivo is very familiar to me. And having lately opened it on six different occasions for the study and treatment of the very distressing condition due to displacement of a semilunar cartilage, I should like to place on record exactiy what has been found as a small contribution to the anatomy of the joint as well as its pathology. The subject deserves a much wider study than would be possible in a paper such as the present.

The clinical history of these cases is the first factor in throwing light upon the mode of production of the injury and the movements of the semilunar cartilage. In the first place, in all the many cases which I have seen, besides those I have operated on, the displacement has been progressivethat is, it has been very slight at first and has gradually increased until complete. In the next it has, I believe, invariably been the internal meniscus which has been displaced. Out of many dozens of these cases which I have seen I cannot recall a single one in which the external cartilage was dislocated. And in all those I have operated on it was clearly seen that the internal was the part out of place. Again, by far the largest number of cases have been among males in my experience, and $I$ have never yet been called upon to operate on a female. The condition has been usually seen among young and vigorous men, my oldest patient being forty-four years of age. This was the only case in which a severe injury appeared to have been the commencement of the lesion. Here (Case 2) the patient had severely twisted his knee by a fall out of a truck. But the ultimate dislocation probably did not take place upon this occasion, but the injury only prepared the way. In every case the bistory of the initial lesion was almost always identically the same. The patients were either walking quietly on the level, or, if we include cases not operated on, were slowly sauntering upstairs, getting out of a bath, mounting or dismounting from a bicycle or horse, and a slight catch was felt on the inner side of the joint. In all, the displacement occurred while the knee was very slightly flexed, and usually while there was very little muscular effort being put out. In one case, it is true, the patient was playing foctball when his knee "gave." Then there was a history in all cases of recurrent attacks like the first at ever-shortening intervals and each time with more severe symptoms. In some cases where the descriptions were particularly accurate the patients noted the "slipping out" to have occurred while the limb was not only slightly flexed, but at the same time the leg was rotated outwards on the thigh. This I believe to be the rule. In the less marked cases the first and second attacks left but little ill effects behind and extension was as good as before, but usually much swelling due to synovitis followed subseqnent attacks and ultimately remained for a long time. In the severe cases verified later by operation there was a history of a very sharp attack after the first two or three milder ones, and after this there was inability to extend the knee fully, and usually permanent effusion. In none could any foreign body be feit in the knee, and any palpable evidence of the absence of the meniscus from its usual place was rot discoverable by the finger. In the examination of the knes and remedy of the displacement the same operation was parformed in every case.

With the limb extended a curved incision reaching from the inner border of the ligamentum patellæ to the anterior edge of the lateral ligament was first made. The ends of this incision in all cases corresponded to a line a little above the level of the upper rim of the tibia; the convexity of the flap reached down for about one inch on the head of the latter. The pericsteum was raised with the flap, which also, of course, contained the capsule besides, but the fibres of the latter were left intact in their relation to the periosteum. This I believe to be most important for the subsequent strength of the joint. When this flap was raised the cartilaginous rim of the articular facet was in every case seen to be divested of its covering semilunar cartilage, and except in Cases 1 and 4 the latter could not be seen at all with the limb in the extended position. In these two cases the meniscus was seen to be detached only in the outer part of its periphery from the capsule, and to have slipped in more or less between the bones. But in neither case had it disappeared from view. But in the other four cases when the joint was opened as above no semilunar cartilage was to be seen at all with the knee extended. The flap turned up showed where it had been detached, but the meniscus itself had disappeared. Bat when the joint was flexed to about a right angle it became possible to see the loosened mass lying in the inter-condyloid notch against the cracial ligaments. In three out of the four in which it was found in this condition of complete inward dislocation it was only held by its extreme ends; in the last case there was still a trace of its capsular union anteriorly. In all these cases of entire dislocation inwards the reduction was effected by a pull forwards with a sharp hook, the knee being strongly flezed. And it was remarkable how strong the traction required to be in order to restore the meniscus to its proper position. It always came out with a slip suddenly, and the knee could then be fully extended. But quite as remarkable as the need of strong traction to bring it out was the tendency it had to return to the inter-condyloid notch when the knee was slightly flexed. It appeared to be dragged in suddenly during flexion, and if the hook were left loose it would carry it with it. This was so remarkable that I demonstrated it over and over again in more than one case to those present. It was easy to see in all these movements of the knee that in those cases in which the meniscus was rolled up in the middle of the joint nothing short of traction with a hook could have yrought it into the normal position; but in Cases 1 and 4 , where only part of the peripheral attachment had given way, replacement in slight flexion was quite easy.

From a study of these cases I have satisfied myself, therefore, that where I have been successful in reducing a semilunar cartilage by manipulation without opening the joint the dislocation must have been incomplete, and, indeed, comparatively trifling, only a part of the capsular attachment having been torn, or, perhaps, only stretched. The other cases $(2,3,5$, and 6$)$ all showed that no manipulation or movement of the joint could ever have restored the meniscus to its original position. These six cases operated on showed the derangement of the joint in every stage when taken in the following order-1, 4, 6, 3, 5, and 2. Case 1 showed detachment of part of the periphery and very moderate displacement. Case 4 showed a wider separation of the meniscus from the capsule and greater displacement; the other cases al showed complete dislocation into the inter-condyloid notch. In Case 6 there was still, however, a trace of the capsular attachment left anteriorly, but in the rest the latter had quite given way and the cartilages were only held by their ends. But in Case 2, not only was this the case, but the meniscus, from long dislocation, had altered materially in shape and appeared corrugated so as to accommodate itself to its new position. I find, too, in the notes that it appeared to have contracted adhesion in its new position; and perhaps this was the case, but I suspect that the difficulty in drawing it out and in keeping it fixed during suture of its edge was more due to its being crumpled and perhaps shrunken somewhat. This fact of crumpling and shrinkage probably explains, too, the longer time taken by this patient to recover the free use of his knee than in any of the others. It will also doubtless explain the great amount 
of effusion into the joint which took place in this case after operation, and which required aspiration of the synovium two or three times within the first few weeks. And even now, though the man is running about quite well at his work, and very cheerful about his leg, there is still some slight stiffness in moving the joint. Of course, this was the oldest patient of the series, and the dislocation was of longer standing than in the other cases, except Case 5, factors which no doubt told on convalescence and completeness of recovery. In the other cases of younger men in whom the condition had not, with the exception of Case 5 , lasted so long, the recovery was more perfect, and the reaction in the joint after operation practically nil. In Case 5 there was considerable reaction and slow recovery of power. It happens that within the last few weeks I have heard from several sources of Case 1. This young officer is now in India and taking part in all the exercises of his profession and in athletics as if his knee had never been injured. Case 3 has been lost sight of, but the last note in the hospital record was, "Joint looks quite normal." Case 4 I have seen and heard of several times since operation. He is rejoicing in complete restoration of the joint. Case 5 is that of a young naval officer who is back at his work and able for it. There was a considerable swelling on the inner side of the joint when I last saw him nine months after operation and still some stiffness. He was then still nervous about using the limb to its fullest extent, but unnecessarily so. ${ }^{1}$ In this case there was great displacement, and the condition had lasted for a considerable time, three years probably, as in Case 2. The consequence was much alteration in the meniscus while displaced. Case 6 is still under observation. His convalescence has been absolutely uneventful; there was no reaction at all in the joint after operation, and he is beginning free movement. In this case, though there was complete dislocation, I expect a more than usually good result for the operation was performed within three days of that attack which resulted in dislocation.

It was very interesting to note in all these instances that the patients' statements that in many cases the joint "went out" during slight flexion and eversion were confirmed by observation of the movements of the semilunar cartilage during ilexion and extension in vivo. On looking into the joint after reducing the meniscus the latter was always seen to move inwards during flexion. This was not merely a simple slipping inwards, but a dragging inwards, which could be felt when a hook was inserted in the meniscus itself; and in the cases in which the detachment was marked the cartilage was plainly dragged into the middle of the joint with the hook and with considerable force. Slight flexion began the morement, which seemed to increase the more the knee was bent, until finally the meniscus slipped over the convexity of the femur and got between the condyles and remained there.

Through the kindness of my colleague, Professor Thane, $T$ have been able more than once lately to examine a number of variously dissected knee-joints, and in these, too, the movement of the cartilage backwards and inwards during flexion can be seen to a certain extent, but far less marked than in the living knee. But the mechanism of the movement is far from clear eitner in the dead or living joint. What appears to take place is this. In the first place during flexion the point of contact between the femur and tibia appears to shift backwards a little. This in itself would relieve the pressure on the anterior curve of the meniscus and push the posterior surve backwards. But in addition it would incline the internal lateral ligament somewhat backwards, and in this way drag the semilunar cartilage back through its attachment to the lateral ligament. Apparently one at least of the functions of the posterior crucial ligament is to prevent the femur from slipping too far backwards, for it is rendered tense in flexion. Whether this explanation of the causes of the displacement of the meniscus be correct or no the fact remains that during flexion in the living joint it can be seen to slip backwards. The actual dislocation, of course, is due to the nipping of its edge when the limb is extending, which fixes it between the two bones and prevents it travelling forwards, while the capsule, being rendered tense by extension, is torn away from it more and more until there is nothing to prevent it slipping into the midale of the joint. Whether when it has once been completely dislocated thus it

1 Since this was written $I$ have heard by letter from this patient from the Red Sea. He is now quite well.

the patient $H$ is int is reriectly normal in every way, and he is able for every kind of exercise. ever returns to its normal position is, I think, donbtful. I imagine that in those cases in which it has been supposed to do so the dislocation has not been completely into the centre of the joint, but has been a partial nipping. The appearance of the meniscus in those cases in which I have seen it lying against the crucial ligaments was certainly such that its return without considerable traction appeared an impossibility. It was puckered, thickened, and apparently shrunken.

From all this it would appear that given a knee-joint in which this derangement has taken place incontestably and has been repeated an operation ought to be performed without delay so as to prevent the complete dislocation from taking place. If the latter has occurred there is the more reason for immediate interference before the semilunar cartilage becomes altered in shape and texture. In such cases the manipulations during operation must be more severe and the reaction thereafter more decided, while a complete restitutio ad integrum is much less likely owing to the changes in the cartilage and other structures of the joint. If the operation is not performed reasonably early there is a danger of the displaced cartilage being so seriously altered in texture and shape that it cannot be restcred to position, and nothing remains but to excise it completely and leave the joint without an internal meniscus.

The following six consecutive cases form an interesting roup.

CASE 1.-The patient, aged twenty-four years, while playing rackets in April, 1895, slipped, "and felt something go in his right knee." He had sharp pain, and the joint swelled up and he could not bend it. This swelling lasted a month, when he thought the cartilage must have gone back into position, for the swelling suddenly went down; but soon after he had a return of symptoms. He was then put in splints. Recovery again took place, but three weeks later the same "slip" occurred. He was then invalided. Since then he had put the knee out five times, and on each occasion swelling has followed. The operation was performed on Oct. 3rd, 1895, in the same manner as in the other cases. The cartilage was only partially separated from the capsule and was drawn out with a book and stitwhed to the posterior surface of the flap raised. The silk stitches were used, which at first tended to out out of the cartilage. The wound was closed in the way described and dressed with salicylic wool. There was no drainage. Primary union took place with very slight synovitis.

CASE 2.-A man, aged forty-four years, had been always healthy and with a good family history. He strained his left knee a year previously in a fall from a truck. Three months later, while walking, he felt pain in the same knee, but after a few seconds he was able to put it straight again. Similar attacks had ocsurred every two or three weeks since. In October, 1895, he had a bad attack and was unable to straighten the limb for about three weeks, the joint at the same time being very much swollen. He was unable to walk for six weeks and three days; after he began to go about the knee locked as before and he was off work for five weeks. The patient was a robust and finely developed man ; there was no enlargement of the joint and nothing otherwise abnormal about the knee to be felt. He was able to walk except when the cartilage was displaced. The operation was performed on Feb. 20th, 1896, in the same manner as the other cases. When the joint was opened the semilunar cartilage was found to be torn away from the capsule all round and to be curled up against the crucial ligaments in the intercondyloid notch, where it had contracted adhesions. When it was drawn into its normal position by means of a blunt hook with the knee slightly flexed it could be retained there by full extension of the joint, but upon the slightest flexion it slipped back into the old position, dragging the hook with it with some force. Six fine silk sutures were inserted through its outer border, and it was stitched to the flap of the capsule and periosteum as in the other cases. This flap was then sutured in situ, and the wound was closed without drainage. There was a good deal of pain in the joint next day, bat this soon passed off. The first dressing was on the sixth day, when all the wound but its two ends was found united per primam. There was a good deal of fluid in the joint. On the tenth day the wound was perfectly healed and the fluid, consisting of yellow serum, was aspirated. Four days later the joint was again aspirated, as the fluid had reaccumulated to the extent of three ounces. About this time there was mild lymphangitis with tenderness up the thigh and in the groin. The wound, however, remained perfectly quiet. There was throughout retention of urine requiring 
the catheter. Either owing to the lymphangitis, or perhaps the retention, the temperature was raised for fifteen days, on one occasion to $1022^{\circ} \mathrm{F}$. It then fell, and convalescence was uninterrupted farther. Under massage the swelling of the joint improved much before the patient was discharged on April $4 \mathrm{th}$. I have since seen him several times. He is now at work and with a good knee. There is slight limitation of extreme flexion and a trace of swelling. Otherwise nothing is to be noticed, and he expresses much satisfaction with the result.

CASE 3. - A man, aged thirty eight years, had always been healthy and had a good family history except that his father died from "consumption." In January, 1896, he felt the left knee "give" while walking quietly. After this the joint swelled and he used a liniment. At the end of a fortnight he could get about without any abnormal sensation in the joint except the "slipping of something" occasionally, but the swelling remained with pain and throbbing and an occasional crack for a time. When seen there was no pain, but the joint was somewhat enlarged with flaid. Flexion produced no pain. The operation was performed on May 1st, 1896, in the same manner as in the other cases. Here, too, the semilunar cartilage was found to have completely slipped into the inter-condyloid notch, from which it could only be drawn out into position by means of a hook and retained by full extension of the joint. When the latter was slightly flexed it at once suddenly slipped back to the cruoial ligaments. It was fixed by four silk sutures in situ, and the wound was closed without drainage. There was much pain during the following night and little sleep. This lasted for a day or two, being most marked at night. On the sixth day the first dressing was changed and union per primam was found, the joint looking quite normal. Collodion and wool were applied. The skin stitches were removed on the ninth day, and the knee was massaged daily. He left the hospital on June 6th quite well. The temperature on the first and second days rose to $1002^{\circ} \mathrm{F}$., and then fell to practically normal. Convalescence was uninterrupted. I have not seen or heard of the patient since his discharge.

CASE 4.-A man, aged forty years, had always been healthy and very active. While playing football four months previously he felt his left knee give way under him while he was kicking the ball with his right foot. At the same moment he felt something slip in the joint, which was followed by great pain. He was compelled to rest for a month, and was then able to use the le $\mathrm{g}$ as before, but it was weak. A fortnight later he felt the same twist while bowling at cricket, but less severely than the first. Notwithstanding, in spite of keeping his bed for fourteen days, recovery was not so rapid and complete as before. A week before admission to University College Hospital, on June 23rd, 1896, exactly the same accident happened to his knee while leaning forward on a prop fixed in the ground. Since then he bad kept his bed. On admission the knee was kept slightly flexed with a slight degree of rotation outwards. Flexion produced no pain. There was slight wasting of the thigh. The operation took place on July 2nd, 1896. The semilunar cartilage was only separated from the capsule at its posterior and inner aspect, and only slightly displaced inwards. Similar sutures and dressing to those in the other cases were used, and there was no drainage. The temperature rose gradually day by day to $101.2^{\circ} \mathrm{F}$. on the seventh day, and then gradually fell to normal. Healing took place per primam except at ore point, where one of the deep silk ligatures projected a little. 'The patient went home on Jaly 31 st. He returned to show himself some weeks later. $\mathrm{He}$ was walking well and was very cheerful about himself. One of the deep ljgatures was seen projecting from a moist spot in the scar. This I removed. I have seen the patient since quite well and with a perfectly sound knee.

CASE 5.--A young naval officer had the usual history of several more or of less severe attacks in the right knee which had commenced three years before. The knee was slightly flexed and could not be extended fully, but there was not much pain and only trifling thickening round the joint. Nothing abnormal could be felt on the borders of the joint. On April 16th, 1896, I operated as before described and found the massive semilunar cartilage lying, bent and twisted, between the condyles. When drawn out with a hook it showed the greatest tendency to recoil to its old vicious position, and, in fact, did so when the $h$ rok was left to itself. This was so remarkable that I asked my friend, Dr. Dadley Buxton, who was giving chloro- form, and who had seen my other cases, to come round from the patient's head and look at it. The meniscus was stitched in position, as in the other cases, and the wound closed withcut drainage. The wound healed per primam, but there was some fffusion into the joint which absorbed slowly. When seen last Christmas there was still slight stiffness, but relief was otherwise complete. He is now abroad and quite well.

CASE 6.-A healtby young man, aged twenty-one years, first noticed a sharp click in his right knee while vaulting over a bar three years ago. There was pain at the same time, but this soon passed off. He experienced the same sensation shortly after. Finally, on May 20d, 1897, two days before admission, while playing in a field and starting to run, his knee suddenly gave out, and he found he could not extend it easily or walk with any comfort. $\mathrm{He}$ was obliged to keep it somewhat flexed. On admission he complained of inability to extend the right knee, which was kept in a state of flexion, but could be moved in greater flexion without pain. There was no swelling of the joint, and nothing abnormal could be felt. On May 4th I operated precisely as in the other cases, and found the meniscus curled up in the inter-condyloid notch torn from its capsular attachments, except just at its anterior curve. It was reduced in flexion with a hook, and the rest of the operation was soon finished. There was absolutely no reaction in the joint, and when the superficial sutures were removed on the twelfth day primary union was complete.

Harley-street, W.

\section{THE ROENTGEN RAYS IN MEDICAL, DIAGNOSIS.}

BY H. CAMPBELL THOMSON, M.D., M.R.C.P.LOND. MEDICAL REGISTRAR TO THE MIDDLESEX HOSPITAL.

THE following cases are of some interest in showing the value of the Roentgen rays in medical diagnosis. In all of them the fluorescent screen was used, as it is more certain and far less tedious than photography for making examinations of the chest. The diagrams show the appearances of the cases as seen upon the screen; the ribs and sternum, which in reality appear dark, have been left clear in the diagrams in order to avoid ccnfusion.

CASE 1.-A man, aged forty-nine years, was admitted into the Middlesex Hospital complaining of paroxysmal attacks of pain in the chest which had occurred on and off for the past. five years, On admission the physical signs were as follow: the apex beat of the heart was in the fifth interspace, but

FIG. 1.

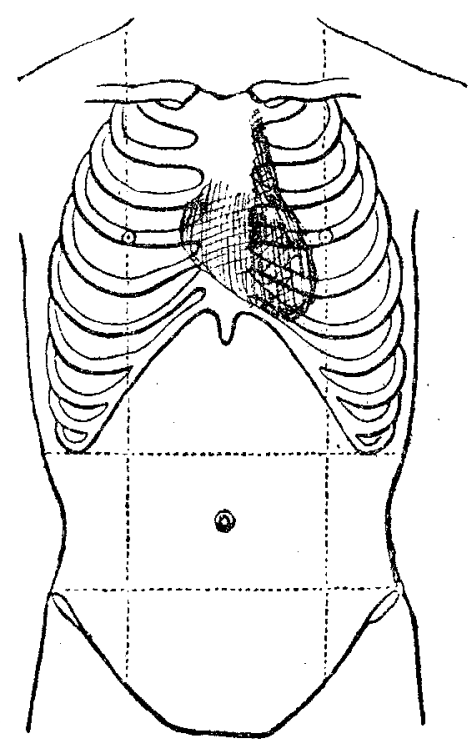

The shadow of the heart is seen extending up the left side of the sternum up to the first rib.

displaced a little outwards, so that it was in the vertical line of the nipple. The first sound was weak, but the second sound at the aortic base was loud and ringing in quality and was accompanied by a systolic murmur. The percussion note over the manubrium sterni was impaired, and some slight pulsation could also be felt over this area. The voice was. rather hoarse occasionally, but a laryngeal examination showed that both the cords moved freely. Over the 